\title{
Further considerations of two-dimensional condensation drop profiles and departure sizes*
}

\author{
H. Merte, Jr. and S. Son, Ann Arbor, Michigan, USA
}

\begin{abstract}
The problem of the equilibrium shape and departure size of two-dimensional dropwise condensation drops on a vertical surface, presented in an earlier work, is extended to include advancing contact angles to $180^{\circ}$. The equation of the surface of the drop is obtained by minimizing (for a given volume) the total energy of the drop, consisting of surface and gravitational energy, using the techniques of variational calculus. The solution is tractable once the advancing contact angle is known, and is taken as an approximation to the axial meridian profile of a threedimensional drop. The receding contact angle is obtained as part of the solution.

The drop size is specified by imposing its vertical length in contact with the wall. A maximum value of this length exists which provides a real solution, and this is taken as the departure size of the drop. It is shown that the general departure shape for an advancing contact angle of $180^{\circ}$ includes the cases for all advancing contact angles.
\end{abstract}

Weitere Überlegungen zur zweidimensionalen Kondensation,
Tropfenprofile und Abreißgrößen

Zusammenfassung. Das bereits in einer früheren Arbeit behandelte Problem der Gleichgewichtsform und der Abreißgröße eines Kondensationstropfens an einer senkrechten Fläche wird hiermit auf Vorrückwinkel bis zu $180^{\circ}$ erweitert. Die Gleichung für die Tropfenoberfläche wird dabei durch Minimierung der Gesamtenergie des Tropfens (bei gegebenem Volumen), die ihrerseits die Oberflächen und die Gravitationsenergie enthält, mit Hilfe der Variationsrechnung bestimmt. Dabei erfordert die Lösung für den zweidimensionalen Tropfen lediglich die Kenntnis des Vorrückwinkels. Sie kann dann als Näherung für den axialen Meridian-Schnitt eines dreidimensionalen Tropfens verwendet werden. Dabei ergibt sich der Rückzugswinkel des Tropfens als ein Teil der Lösung.

Die Tropfengröße ist bestimmt durch die vertikale Kontaktlänge an der Wand. Einen Maximalwert dieser Länge erhält man aus der Forderung, daB die Lösung noch reell bleibt. Die derart ermittelte Länge wird als maßgebliche Abreißgröße des Tropfens angesehen. Schließlich wird gezeigt, daß die allgemeine Abreißform bei einem Vorrückwinkel von $180^{\circ}$ auch alle Fälle anderer Vorrückwinkel enthält.

\section{Nomenclature}

a acceleration

A drop cross section area

* Dedicated to Prof. Dr.-Ing. U. Grigull's 75 th birthday

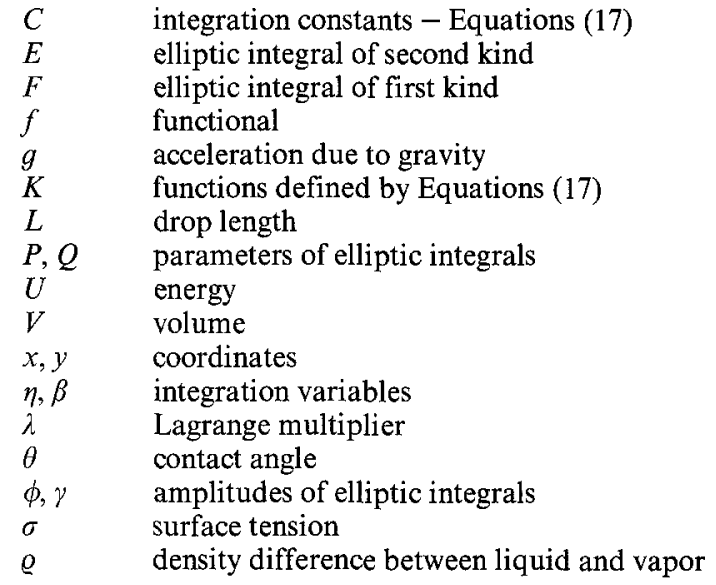

Subscripts

$\begin{array}{ll}A & \text { advancing } \\ d & \text { departure } \\ l & \text { liquid } \\ M & \text { maximum } \\ o & \text { shifted origin } \\ r & \text { relative coordinate } \\ R & \text { receding } \\ S & \text { solid } \\ v & \text { vapor } \\ * & \text { dimensionless } \\ - & \text { new functional }\end{array}$

\section{Introduction}

This is an extension of the work presented in [1], in which the general profile of a two-dimensional drop on a vertical surface was computed, with the departure profile and size being obtained as a special limit. The two-dimensional profiles were taken to be approximations to the mid-plane profiles of drops, and good comparisons between computed departure sizes and measurements made at earth and high gravity fields simulated by centrifugal acceleration. The equilibrium profile, including the receding contact angle, is determined as a function of drop size and 
advancing contact angle, using variational principles. Because of difficulties in dealing with a multivalued function associated with advancing contact angles greater than $90^{\circ}$, the results of the analysis presented in [1] are limited to advancing contact angles in the range $0 \leqq \theta \leqq 90^{\circ}$. This difficulty has now been overcome, and in the present work the equilibrium profiles are obtained for advancing contact angles in the range $0 \leqq \theta \leqq 180^{\circ}$.

\section{Analysis}

For purposes of clarity and convenience, the pattern of development paralleling that of [1] will be followed here, modified as necessary to incorporate the extension to larger advancing contact angles.

Using the coordinate system for the two-dimensional cylindrical drop shown in Fig. 1, expressions are sought for $y_{1}(x)$ covering the outer surface from the receding contact angle taken as the origin to the lowest point with vertical length $L_{M}$ and for $y_{2}(x)$ covering the inner surface on the wall with vertical length $L$ plus the remainder from the advancing contact angle to the lowest point. For $\theta_{A} \leqq 90^{\circ}, L_{M}=L$ and $y_{2}(x)=0$, the case covered in [1]; the integrals for total energy of the drops have common limits directly. For $90^{\circ} \leqq \theta_{A} \leqq 180^{\circ}, L_{M} \geqq L$ and $y_{2}(x) \neq 0$; the integration limits are made common by certain rearrangements presented below.

The total energy of the drop is due to:

(a) the work of adhesion between the liquid drop and surrounding vapor, given by:

$$
\begin{aligned}
U_{l v}= & \int_{-L_{\boldsymbol{U}}}^{0} \sigma_{l v} d S_{1}+\int_{-L_{\boldsymbol{M}}}^{-L} \sigma_{l v} d S_{2} \\
= & \int_{-L_{\boldsymbol{M}}}^{0} \sigma_{l v}\left[1+\left(\frac{d y_{1}}{d x}\right)^{2}\right]^{1 / 2} d x \\
& +\int_{-L_{M}}^{0} \sigma_{l v}\left[1+\left(\frac{d y_{2}}{d x}\right)^{2}\right]^{1 / 2} d x \\
& -\int_{-L}^{0} \sigma_{l v}\left[1+\left(\frac{d y_{2}}{d x}\right)^{2}\right]^{1 / 2} d x .
\end{aligned}
$$

In the last term of Eq. (1), $\left(\frac{d y_{2}}{d x}\right)=0$ within the integration limit.

(b) The work of adhesion between the drop and the solid surface:

$$
U_{l s}=\int_{-L}^{0}\left(\sigma_{s v}-\sigma_{l s}\right) d x
$$

(c) Gravitational potential energy:

$$
\begin{aligned}
U_{g} & =\int_{-L_{M}}^{0} x \varrho g y_{1} d x-\int_{-L_{\boldsymbol{M}}}^{-L} x \varrho g y_{2} d x \\
& =\int_{-L_{M}}^{0} x \varrho g\left(y_{1}-y_{2}\right) d x .
\end{aligned}
$$

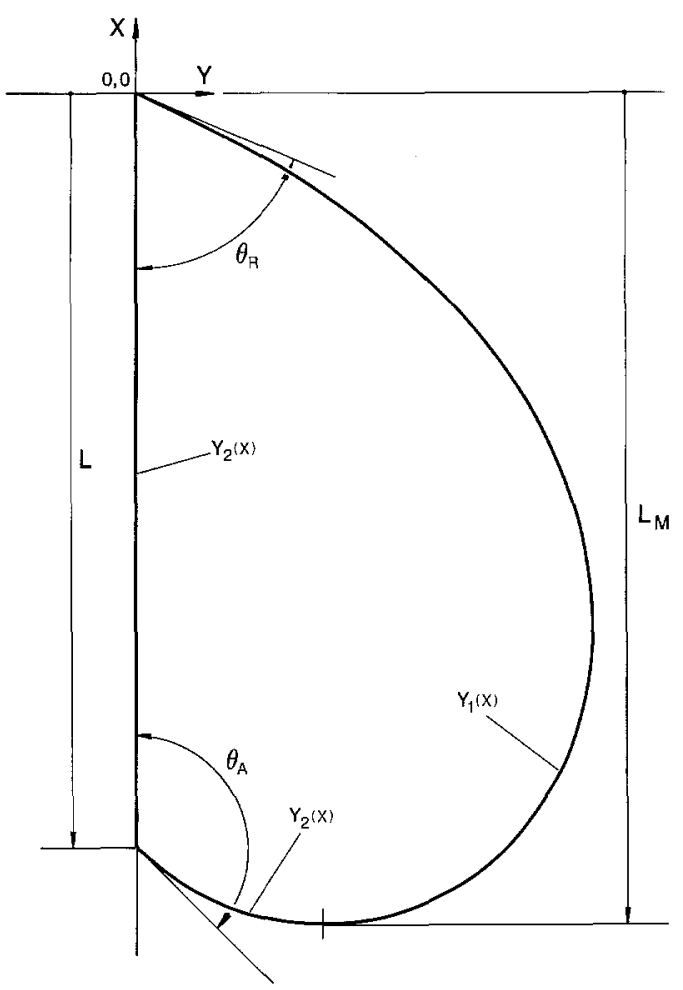

Fig. 1. Coordinate system for drop on a vertical surface

The volume of the drop is:

$V=\int_{-L_{M}}^{0} y_{1} d x-\int_{-L_{M}}^{-L} y_{2} d x=\int_{-L_{M}}^{0}\left(y_{1}-y_{2}\right) d x$.

In Eqs. (3) and (4), $y_{2}(x)=0$ over the limit 0 to $-L$. All quantities are on a per unit width basis.

For generality, the variables will be made dimensionless using $\sigma_{l v}$ for surface energies and $\left(\sigma_{l v} / \varrho g\right)^{1 / 2}$ for lengths, as:

$$
\begin{array}{ll}
x^{*}=\frac{x}{\left(\sigma_{l v} / \varrho g\right)^{1 / 2}} ; \quad y^{*}=\frac{y}{\left(\sigma_{l v} / \varrho g\right)^{1 / 2}} ; \quad L^{*}=\frac{L}{\left(\sigma_{l v} / \varrho g\right)^{1 / 2}} \\
L_{M}^{*}=\frac{L_{M}}{\left(\sigma_{l v} / \varrho g\right)^{1 / 2}} ; \quad \sigma_{v}^{*}=\frac{\sigma_{s v}}{\sigma_{l v}} ; \quad \sigma_{l}^{*}=\frac{\sigma_{l s}}{\sigma_{l v}} \\
U^{*}=\frac{U}{\left(\sigma_{l v}^{2} / \varrho g\right)} ; \quad V^{*}=\frac{V}{\left(\sigma_{l v} / \varrho g\right)^{3 / 2}} .
\end{array}
$$

In these terms, the total energy and volume per unit width of the drop, converted to common integration limits, are given by:

$$
\begin{aligned}
& U^{*}=\int_{-L_{\text {* }}^{*}}^{0}\left\{\left[1+\left(\frac{d y_{1}^{*}}{d x^{*}}\right)^{2}\right]^{1 / 2}+\left[1+\left(\frac{d y_{2}^{*}}{d x^{*}}\right)^{2}\right]^{1 / 2}\right. \\
& \left.\quad+\left(\sigma_{v}^{*}-\sigma_{l}^{*}-1\right) \frac{L^{*}}{L_{M}^{*}}+x^{*}\left(y_{1}^{*}-y_{2}^{*}\right)\right\} d x^{*} \\
& V^{*}=\int_{-L_{\mathbf{M}}^{*}}^{0}\left(y_{1}^{*}-y_{2}^{*}\right) d x^{*} .
\end{aligned}
$$


The total energy of Eq. (6) can be expressed in the following form with the functional $f$ for the purpose of applying variational methods:

$$
U^{*}=\int_{-L_{3}^{*}}^{0} f\left(x^{*}, y_{1}^{*}, y_{2}^{*}, \frac{d y_{1}^{*}}{d x^{*}}, \frac{d y_{2}^{*}}{d x^{*}}\right) d x^{*} .
$$

The asterisks $\left(^{*}\right)$ will be omitted and all quantities understood to be dimensionless.

To minimize the total energy in Eq. (6), its first variation $\delta U$ must vanish, and the necessary condition is that the functional $f$ in Eq. (8) must satisfy the Euler equation [2]:

$$
\frac{\partial f}{\partial y}-\frac{d}{d x}\left(\frac{\partial f}{\partial y^{\prime}}\right)=0
$$

To satisfy the constraint of constant volume given by Eq. (7), the undetermined Lagrangian multiplier $\lambda$ is introduced to produce a new functional:

$$
\hat{f}\left(x, y_{1}, y_{2}, y_{1}^{\prime}, y_{2}^{\prime}\right)=f\left(x, y_{1}, y_{2}, y_{1}^{\prime}, y_{2}^{\prime}\right)+\lambda\left(y_{1}-y_{2}\right) \text {. }
$$

Substituting from Eq. (6) this becomes:

$$
\begin{gathered}
\hat{f}\left(x, y_{1}, y_{2}, y_{1}^{\prime}, y_{2}^{\prime}\right)=\left\{\left[1+\left(\frac{d y_{1}}{d x}\right)^{2}\right]^{1 / 2}+\left[1+\left(\frac{d y_{2}}{d x}\right)^{2}\right]^{1 / 2}\right. \\
\left.+(x+\lambda)\left(y_{1}-y_{2}\right)+\left(\sigma_{v}-\sigma_{l}-1\right) \frac{L}{L_{M}}\right\} .
\end{gathered}
$$

The problem now is to find the extremum of:

$$
U+\lambda V=\int_{-L_{M}}^{0} \hat{f}\left(x, y_{1}, y_{2}, y_{1}^{\prime}, y_{2}^{\prime}\right) d x
$$

or

$\delta(U+\lambda V)=0$.

The two Euler equations to be satisfied now are:

$\frac{\partial \hat{f}}{\partial y_{1}}-\frac{d}{d x}\left(\frac{\partial \hat{f}}{\partial y_{1}^{\prime}}\right)=0$

$\frac{\partial \hat{f}}{\partial y_{2}}-\frac{d}{d x}\left(\frac{\partial \hat{f}}{\partial y_{2}^{\prime}}\right)=0$.

Substituting Eq. (11) in Eqs. (14a) and (14b), the governing equations for the interface profiles are obtained:

$$
\begin{gathered}
(x+\lambda)-\frac{d}{d x}\left\{\frac{d y_{1} / d x}{\left[1+\left(d y_{1} / d x\right)^{2}\right]^{1 / 2}}\right\}=0 \\
-(x+\lambda)-\frac{d}{d x}\left\{\frac{d y_{2} / d x}{\left[1+\left(d y_{2} / d x\right)^{2}\right]^{1 / 2}}\right\}=0 .
\end{gathered}
$$

Integrating Eqs. (15) and rearranging:

$$
\begin{aligned}
& \frac{d y_{1}}{d x}=\frac{K_{1}(x)}{\left[1-K_{1}^{2}(x)\right]^{1 / 2}} \\
& \frac{d y_{2}}{d x}=\frac{K_{2}(x)}{\left[1-K_{2}^{2}(x)\right]^{1 / 2}}
\end{aligned}
$$

where

$K_{1}(x)=\frac{1}{2}(x+\lambda)^{2}+C_{1}$

$K_{2}(x)=-\frac{1}{2}(x+\lambda)^{2}+C_{2}$

and $C_{1}$ and $C_{2}$ are integration constants to be determined, along with $\lambda$ from boundary conditions. Eq. (16) give the slopes of the profile as a function of $x$. The value at $x=0$ with Eq. (16a) will be the receding contact angle $\theta_{R}$, and the value at $x=-L$ with Eq. (16b) will be the advancing contact angle $\theta_{A}$.

The drop profile is obtained by integrating Eqs. (16), and can be placed into the following forms when the change of variables is made letting $\eta=K_{1}$ and $\beta=K_{2}$ of Eqs. (17).

$y_{1}=\frac{1}{\sqrt{2}} \int_{K_{1}}^{K_{1}(0)} \frac{\eta d \eta}{\left(1-\eta^{2}\right)^{1 / 2}\left(\eta-C_{1}\right)^{1 / 2}}$

$y_{2}=\frac{-1}{\sqrt{2}} \int_{K_{2}}^{K_{2}(-L)} \frac{\beta d \beta}{\left(1-\beta^{2}\right)^{1 / 2}\left(C_{2}-\beta\right)^{1 / 2}}$

where $K_{1}(0)=K_{1}(x=0)$ and $K_{2}(-L)=K_{2}(x=-L)$. The integrals of Eq. (18) are expressed in terms of elliptic integrals as:

$$
\begin{aligned}
y_{1}=\sqrt{2}\left\{\frac{C_{1}}{\left(1-C_{1}\right)^{1 / 2}}\left[F\left(\phi_{K_{1}}, P\right)-F\left(\phi_{K_{1}(0)}, P\right)\right]\right. \\
\left.+\left(1-C_{1}\right)^{1 / 2}\left[E\left(\phi_{K_{1}}, P\right)-E\left(\phi_{K_{1}(0)}, P\right)\right]\right\}
\end{aligned}
$$

$$
\begin{aligned}
& y_{2}=\sqrt{2}\left\{\frac{C_{2}}{\left(1+C_{2}\right)^{1 / 2}}\left[F\left(\gamma_{K_{2}}, Q\right)-F\left(\gamma_{K_{2}(-L)}, Q\right)\right]\right. \\
&\left.-\left(1+C_{2}\right)^{1 / 2}\left[E\left(\gamma_{K_{2}}, Q\right)-E\left(\gamma_{K_{2}(-L)}, Q\right)\right]\right\}
\end{aligned}
$$

where

$$
\begin{array}{ll}
\phi_{K} & =\operatorname{Arcsin} \sqrt{\frac{1-K_{1}}{2}} ; \quad P=\sqrt{\frac{2}{1-C_{1}}} \\
K_{1} & =K_{1}(x) \quad \text { Eq. (17a)) } \\
K_{1}(0) & =K_{1}(x=0) \\
\gamma_{K_{2}} & =\operatorname{Arcsin} \sqrt{\frac{1+K_{2}}{2}} ; \quad Q=\sqrt{\frac{2}{1+C_{2}}} \\
K_{2} & \left.=K_{2}(x) \quad \text { (Eq. }(17 \mathrm{~b})\right) \\
K_{2}(-L) & =K_{2}(x=-L) .
\end{array}
$$

Rearranging Eq. (16), it can be shown that $K(x)$ of Eq. (17) have the physical significance:

$$
\begin{aligned}
& K_{1}(x)=\sin \theta=\frac{1}{2}(x+\lambda)^{2}+C_{1} \\
& K_{2}(x)=-\sin \theta=-\frac{1}{2}(x+\lambda)^{2}+C_{2} .
\end{aligned}
$$

Thus, at $x=0, C_{1}$ and $C_{2}$ are expressed in terms of $\lambda$, from Eq. (21), as:

$$
\begin{aligned}
& C_{1}=\sin \theta_{R}-\frac{1}{2} \lambda^{2} \\
& C_{2}=-\sin \theta_{A}+\frac{1}{2}(-L+\lambda)^{2} .
\end{aligned}
$$


In the prior work [1] it was demonstrated that in satisfying the transversality condition associated with the variable lower end point, Young's equation was automatically satisfied by the solution provided that the surface energies contained therein are taken to be for the advancing condition. The transversality condition can no longer be applied at the advancing end of the drop since the first derivative of $f_{2}(x)$ at this location is not continuous. Young's equation is no longer satisfied here under any circumstance, and it will simply be taken that the advancing contact angle $\theta_{A}$ is known "a priori".

The conditions which remain to be satisfied can now be expressed. $y_{1}=0$ at $x=0$ and $y_{2}=0$ at $x=-L$ are automatically satisfied by Eq. (19a) and (19b), respectively. At $x=-L_{M}, y_{1}^{\prime}=-y_{2}^{\prime}=\infty$. From Eq. (16) and (17) at $x=-L_{M}$ :

$y_{1}^{\prime}=\frac{\frac{1}{2}\left(-L_{M}+\lambda\right)^{2}+C_{1}}{\left\{1-\left[\frac{1}{2}\left(-L_{M}+\lambda\right)^{2}+C_{1}\right]^{2}\right\}^{1 / 2}}$

$y_{2}^{\prime}=\frac{-\frac{1}{2}\left(-L_{M}+\lambda\right)^{2}+C_{2}}{\left\{1-\left[-\frac{1}{2}\left(-L_{M}+\lambda\right)^{2}+C_{2}\right]^{2}\right\}^{1 / 2}}$.

For $y_{1}^{\prime}\left(-L_{M}\right)=-y_{2}^{\prime}\left(-L_{M}\right)$ one obtains:

$C_{1}=-C_{2}$.

For $y_{1}^{\prime}\left(-L_{M}\right)=y_{2}^{\prime}\left(-L_{M}\right)=\infty$ one obtains:

$C_{1}=1-\frac{1}{2}\left(-L_{M}+\lambda\right)^{2}$

$C_{2}=-1+\frac{1}{2}\left(-L_{M}+\lambda\right)^{2}$.

Given $\theta_{A}$, Eqs. (22b) and (25b) provide a relationship between $\lambda, L$, and $L_{M}$. $L$ can be considered arbitrary thus far since it is related to the size of the drop, and Eq. (22b) and $(25 \mathrm{~b})$ relate $\lambda$ and $L_{M}$. The additional relationship needed comes from Eq. (19) with the requirement that:

$y_{1}\left(-L_{M}\right)=y_{2}\left(-L_{M}\right)$.

Given $\theta_{A}$, from Eq. (23b)

$y_{2}^{\prime}=\tan \theta_{A}=f\left(L_{M}, \lambda\right)$

and Eqs. (26) and (27) can be solved for $\lambda$ and $L_{M}$ as a function of $L$, which must be specified. Once $\lambda$ is known, $\theta_{R}$ can be solved from Eq. (22).

The limits on the solutions of Eq. (18) given by Eq. (19) are formally stated respectively as [3]:

$1>K_{1} \geqq-1>C_{1}$

$C_{2}>1 \geqq K_{2}>-1$.

The present solution is thus valid over the range $0 \leqq \theta_{A} \leqq \pi$.

As was demonstrated in [1], the solution limits of Eq. (19) giving real solutions to the elliptic integrals are taken as giving the departure size and profile on vertical surfaces, or

$C_{1}=-1 ; \quad C_{2}=1 ; \quad P=1 ; \quad Q=1$.
At departure, from Eqs. (25):

$\left(-L_{M d}+\lambda_{d}\right)^{2}=4$.

The elliptic integrals in Eq. (19) reduce to:

$F(\phi, 1)=\ln \sqrt{\frac{1+\sin \phi}{1-\sin \phi}}$

$E(\phi, 1)=\sin \phi$.

Making the substitutions for $\phi$ from Eq. (20) and $K(x)$ from Eq. (17), the profile at departure, from Eq. (19), becomes:

$y_{1 d}=-\frac{1}{2} \ln \left[\frac{\left(1+x^{+}\right)(1-A)}{\left(1-x^{+}\right)(1+A)}\right]+2\left(x^{+}-A\right)$

$y_{2 d}=\frac{1}{2} \ln \left[\frac{\left(1+x^{+}\right)(1-B)}{\left(1-x^{+}\right)(1+B)}\right]-2\left(x^{+}-B\right)$

where

$x^{+}=\left[1-\frac{1}{4}\left(x+\lambda_{d}\right)^{2}\right]^{1 / 2}$

$A=\left[1-\frac{1}{4} \lambda_{d}^{2}\right]^{1 / 2}$

$B=\left[1-\frac{1}{4}\left(-L_{d}+\lambda_{d}\right)^{2}\right]^{1 / 2}$.

From Eq. (22b):

$\sin \theta_{A}=\frac{1}{2}\left(-L_{d}+\lambda_{d}\right)^{2}-1$.

An implicit expression for $\lambda_{d}$ is obtained by substituting Eqs. (30) and (37) into Eq. (33) and noting that $y_{1 d}=y_{2 d}$ at $x=-L_{M d}$.

\section{Sample computations}

Computations of the drop profiles for $\theta_{A}=135^{\circ}$ and for three different values of $L$ are shown plotted in Fig. 2. The corresponding computed values of the receding contact angles are given. The largest value of $L$ shown is that of the departure size $L_{d}$. Using a force balance between gravity and surface tension given by Eq. (43) of [1], the agreement for the departure size of Fig. 2 with the computed $\theta_{R}$ and profile is to six significant figures, using Simpson's Rule with 3200 slices to compute the cross sectional area.

The dimensionless maximum drop length $L_{M d}^{*}$, the drop length in contact with the wall $L_{d}^{*}$ and the receding contact angle $\theta_{R d}$ at departure are plotted in Fig. 3 as a function of the advancing contact angle $\theta_{A}$ over the range $0-180^{\circ}$. It might be noted hat $L_{M d}^{*}$ and $L_{d}^{*}$ are identical over the range $0-90^{\circ}$, and together with $\theta_{R d}$ are identical to the results given in [1].

Setting $\theta_{A}=180^{\circ}$ gives:
$\lambda_{d}=-0.324087$
$L_{d}=1.090126$
$L_{M d}=1.675913$
$\theta_{R d}=-71.349^{\circ}$. 


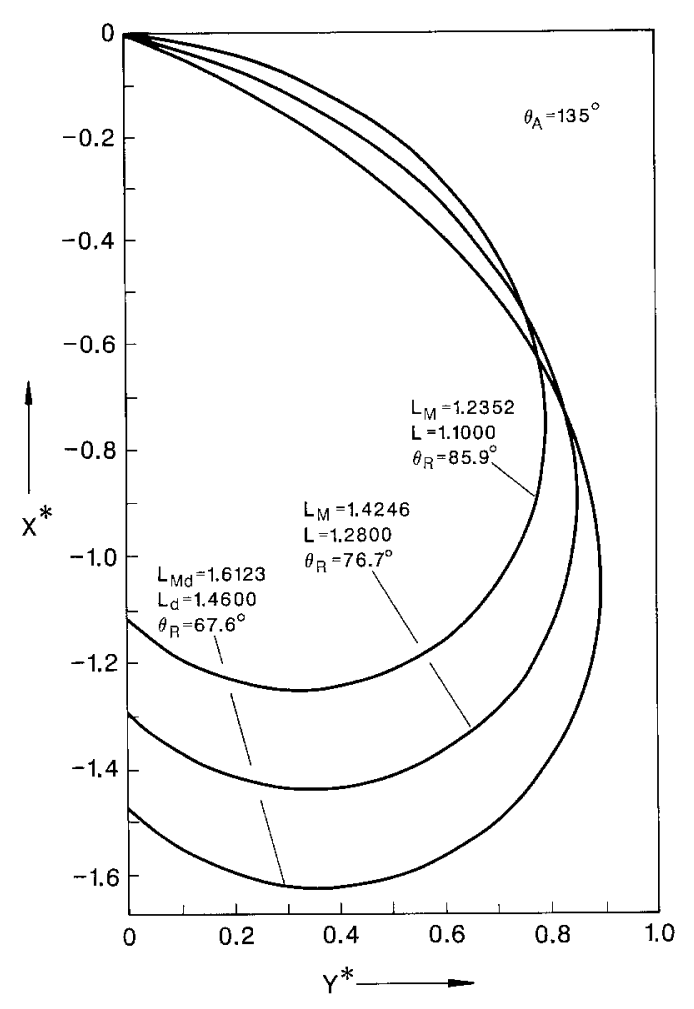

Fig. 2. Sample computations of drop profile

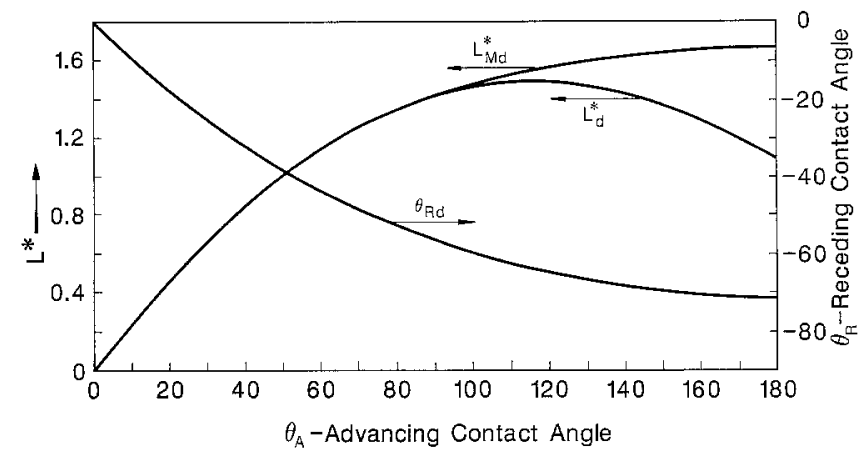

Fig. 3. Variation of departure parameters with advancing contact angle

The dimensionless drop profile at departure computed by Eq. (33) is shown in Fig. 4. The lowest point $L_{M d}$ occurs at $y=0.532840$.

It can be demonstrated that the departure profile for an advancing contact angle of $180^{\circ}$ plotted in Fig. 4 includes the profiles for all advancing contact angles provided the origin for $y^{*}$ is shifted by $y_{0}^{*}$, where the slope is that corresponding to the given advancing contact angle. The relative coordinate to be used is then $y_{r}^{*}$. The origin for $x^{*}$

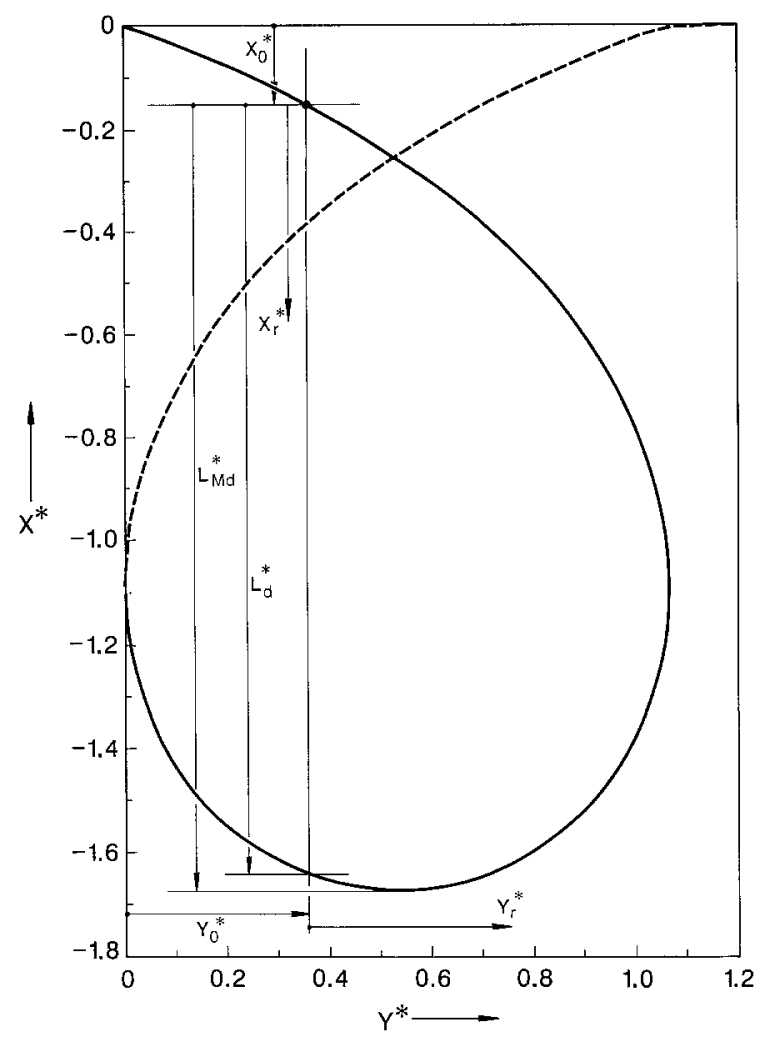

Fig. 4. Dimensionless profile at departure for $\theta_{A}=180^{\circ}$

is shifted by $x_{0}^{*}$ as shown, where the receding contact angle is the slope at this point. The relative coordinate to be used is now $x_{r}^{*}$, and the new lengths $L_{d}^{*}$ and $L_{M d}^{*}$ are as indicated.

It can further be demonstrated that $y_{1 d}$ and $y_{2 d}$ are always symmetrical about the plane passing through the lowest point at $y=0.532840$. Of course, this can also be intuited from hydrostatic conditions in conjunction with satisfying the general Laplace equation of capillarity:

$\Delta P=\sigma_{l v}\left(\frac{1}{R_{1}}+\frac{1}{R_{2}}\right)$.

\section{Conclusions}

The two-dimensional drop form and departure size with dropwise condensation on a vertical surface, computed by variational methods, has been generalized to include advancing contact angles to $180^{\circ}$, and appears to be in reasonable agreement with measurements of drop departure sizes made under various effective gravitational levels, $1 \leqq a / g \leqq 100$ [1]. Non-dimensional results are obtained in a simple form, requiring only the specification of the advancing contact angle. The receding contact angle is obtained as part of the solution. 


\section{References}

1. Merte, H., Jr.; Yamali, C.: Profile and departure size of condensation drops on vertical surfaces. Wärme-Stoffübertrag. 17 (1983) $171-180$

2. Fox, C.: An introduction to the calculus of variations. Oxford University Press 1950

3. Gradshteyn, I. S.; Ryzhik, I.: Table of integrals, series and products. New York: Academic Press 1965
H. Merte, Jr., Prof. of Mechanical Engineering

2148 G. G. Brown Laboratory

S. Son, Research Assistant

Department of Mechanical Engineering and Applied Mechanics

The University of Michigan

Ann Arbor, Michigan 48109, USA

Received September 30, 1986 